\title{
Serum CA 19-9 as a Marker of Resectability and Survival in Patients with Potentially Resectable Pancreatic Cancer Treated with Neoadjuvant Chemoradiation
}

\author{
Matthew H. G. Katz, $\mathrm{MD}^{1}$, Gauri R. Varadhachary, $\mathrm{MD}^{2}$, Jason B. Fleming, $\mathrm{MD}^{3}$, Robert A. Wolff, $\mathrm{MD}^{2}$, \\ Jeffrey E. Lee, $\mathrm{MD}^{3}$, Peter W. T. Pisters, $\mathrm{MD}^{3}$, Jean-Nicolas Vauthey, $\mathrm{MD}^{3}$, Eddie K. Abdalla, $\mathrm{MD}^{3}$, \\ Charlotte C. Sun, DrPH, MPH ${ }^{4}$, Huamin Wang, MD, $\mathrm{PhD}^{5}$, Christopher H. Crane, $\mathrm{MD}^{6}$, Jeffrey H. Lee, $\mathrm{MD}^{7}$, \\ Eric P. Tamm, $\mathrm{MD}^{8}$, James L. Abbruzzese, $\mathrm{MD}^{2}$, and Douglas B. Evans, $\mathrm{MD}^{9}$ \\ ${ }^{1}$ Department of Surgery, Division of Hepatobiliary and Pancreas Surgery, The University of California at Irvine, Orange, \\ CA; ${ }^{2}$ Department of Gastrointestinal Medical Oncology, The University of Texas MD Anderson Cancer Center, Houston, \\ TX; ${ }^{3}$ Department of Surgical Oncology, The University of Texas MD Anderson Cancer Center, Houston, TX; ${ }^{4}$ Department \\ of Gynecologic Oncology, The University of Texas MD Anderson Cancer Center, Houston, TX; ${ }^{5}$ Department of \\ Pathology, The University of Texas MD Anderson Cancer Center, Houston, TX; ${ }^{6}$ Department of Radiation Oncology, The \\ University of Texas MD Anderson Cancer Center, Houston, TX; ${ }^{7}$ Department of Gastroenterology, The University of \\ Texas MD Anderson Cancer Center, Houston, TX; ${ }^{8}$ Department of Diagnostic Imaging, The University of Texas MD \\ Anderson Cancer Center, Houston, TX; ${ }^{9}$ Department of Surgery, The Medical College of Wisconsin, Milwaukee, WI
}

\begin{abstract}
Purpose. The role of carbohydrate antigen (CA) 19-9 in the evaluation of patients with resectable pancreatic cancer treated with neoadjuvant therapy prior to planned surgical resection is unknown. We evaluated CA 19-9 as a marker of therapeutic response, completion of therapy, and survival in patients enrolled on two recently reported clinical trials.

Patients and Methods. We analyzed patients with radiographically resectable adenocarcinoma of the head/ uncinate process treated on two phase II trials of neoadjuvant chemoradiation. Patients without evidence of disease progression following chemoradiation underwent pancreaticoduodenectomy (PD). CA 19-9 was evaluated in patients with a normal bilirubin level.

Results. We enrolled 174 patients, and 119 (68\%) completed all therapy including PD. Pretreatment CA 19-9 $<37 \mathrm{U} / \mathrm{ml}$ had a positive predictive value (PPV) for completing PD of $86 \%$ but a negative predictive value (NPV) of $33 \%$. Among patients without evidence of disease at
\end{abstract}

(C) The Author(s) 2010. This article is published with open access at Springerlink.com

First Received: 15 December 2009;

Published Online: 17 February 2010

M. H. G. Katz, MD

e-mail:katzmh@uci.edu last follow-up, the highest pretreatment CA 19-9 was $1,125 \mathrm{U} / \mathrm{ml}$. Restaging CA $19-9<61 \mathrm{U} / \mathrm{ml}$ had a PPV of $93 \%$ and a NPV of $28 \%$ for completing PD among resectable patients. The area under the receiver-operating characteristics curve of pretreatment and restaging CA 19-9 levels for completing PD was 0.59 and 0.74 , respectively. We identified no association between change in CA 19-9 and histopathologic response $(P=0.74)$.

Conclusions. Although the PPV of CA 19-9 for completing neoadjuvant therapy and undergoing PD was high, its clinical utility was compromised by a low NPV. Decision-making for patients with resectable PC should remain based on clinical assessment and radiographic staging.

Enthusiasm for the use of neoadjuvant therapy for patients with potentially resectable pancreatic adenocarcinoma (PC) has grown as clinicians have increasingly recognized "resectable" $\mathrm{PC}$ as a systemic disease. Neoadjuvant treatment sequencing allows for early treatment of the extrapancreatic micrometastases present in the majority of patients with localized PC and improves the selection of patients for surgery by limiting resection to those with stable or responding disease-an important consideration for an operation with a defined mortality and significant morbidity. ${ }^{1}$ Although no randomized trial has demonstrated the superiority of preoperative over postoperative 
adjuvant therapy, results from single-institution series, multi-institutional trials, and population-based analyses encourage further study of novel treatment sequencing in patients with stage I and II PC. ${ }^{2-6}$

In addition to neoadjuvant treatment sequencing, another tool to more accurately select patients for surgery might be a serum tumor marker. Carbohydrate antigen 19-9 (CA 199) has long been accepted as a measure of PC tumor burden, and as such it has been utilized as a prognostic marker for patients with all stages of disease. ${ }^{7}$ Among patients with resectable PC, preoperative levels correlate with tumor resectability and postoperative survival, and postoperative levels predict survival duration in patients treated with adjuvant therapies. ${ }^{8-12}$ For patients with advanced PC, pretreatment CA 19-9 has been reported to be prognostic and the change in serum levels over the course of treatment has been used as an index of treatment response. ${ }^{13,14}$

Serum CA 19-9 is a useful tumor marker in certain clinical scenarios, but its added prognostic value beyond radiographic and clinical staging for patients with resectable PC is unclear. Moreover, although a few studies have examined CA 19-9 levels of patients who had been treated with chemotherapy or chemoradiation prior to surgery, only one small study has evaluated serial CA 19-9 levels of patients with resectable PC treated with a multidisciplinary program of neoadjuvant therapy and planned resection. ${ }^{15-18}$ To clearly define the role of CA 19-9 in this context, we analyzed patients with potentially resectable PC of the pancreatic head or uncinate process treated on two recently reported phase II trials of neoadjuvant chemoradiation. ${ }^{2,3}$

\section{PATIENTS AND METHODS}

Between 1998 and 2006, 176 patients were enrolled on two neoadjuvant trials. In the first trial (Gem-XRT), induction therapy consisted of seven, weekly intravenous infusions of gemcitabine $\left(400 \mathrm{mg} / \mathrm{m}^{2}\right)$ and concomitant radiation therapy (30 Gy in ten fractions). ${ }^{2}$ Patients on the second trial (Gem-Cis-XRT) received four doses of gemcitabine $\left(750 \mathrm{mg} / \mathrm{m}^{2}\right)$ and cisplatin $\left(30 \mathrm{mg} / \mathrm{m}^{2}\right)$ followed by gemcitabine-based chemoradiation. ${ }^{3}$ Of the 176 patients, we excluded 2 from analysis: 1 with an adenocarcinoma of the ampulla of Vater, and 1 with an adenocarcinoma arising within an intraductal papillary mucinous neoplasm.

Eligibility requirements of both studies were identical. ${ }^{2,3}$ Briefly, all patients had a radiographically visible mass in the pancreatic head or uncinate process and pathologically confirmed adenocarcinoma which was staged as potentially resectable on the basis of objective computed tomography (CT) criteria: (1) no evidence of extrapancreatic disease, (2) absence of tumor extension to the superior mesenteric artery (SMA) or celiac axis, and (3) no evidence of occlusion of the superior mesenteric vein (SMV) or SMV-portal vein (PV) confluence. ${ }^{19}$ When necessary, biliary decompression was accomplished endoscopically. All patients underwent complete restaging evaluation 4-6 weeks following completion of chemoradiation. In the absence of disease progression, patients underwent laparotomy for pancreaticoduodenectomy (PD); the decision to operate was not influenced by CA 19-9. Histopathologic response to preoperative therapy was scored by a gastrointestinal pathologist. ${ }^{20}$ Follow-up was performed on a standard schedule.

Neither trial protocol mandated measurement of serum CA 19-9 but levels were typically measured both prior to (pretreatment level) and following (restaging level) induction therapy. Serum acquired prior to October 6, 2004 was assayed for CA 19-9 by Quest Diagnostics (Madison, NJ). Subsequent samples were assayed using a similar method at The University of Texas M. D. Anderson Cancer Center. Serum CA 19-9 levels obtained in association with total bilirubin $\leq 1.5 \mathrm{mg} / \mathrm{dl}$ were considered evaluable. Levels associated with total bilirubin $>1.5 \mathrm{mg} / \mathrm{dl}$ were excluded from analysis, as biliary obstruction may lead to an increase in serum levels of CA 19-9. ${ }^{7,21}$ CA 19-9 may also not be an accurate reflection of disease status in patients who express the Lewis ${ }^{\mathrm{a}-\mathrm{b}-}$ genotype. $^{22}$ However, genotyping was not performed prospectively and could not be performed retrospectively, so "nonproducers" could not be distinguished from patients who produce CA 19-9 but presented with values below the assay sensitivity threshold $(<8 \mathrm{U} / \mathrm{ml}$ and $<1 \mathrm{U} / \mathrm{ml}$ prior to and after October 6, 2004, respectively). For the purpose of this analysis, below-threshold serum CA 19-9 values were recorded as the threshold value.

Pearson chi-square and Student's $t$ test were used to compare variables. Overall survival was calculated from date of tissue diagnosis and was estimated by the KaplanMeier method. The log-rank test was used to compare survival curves. Receiver-operating characteristics (ROC) curves were constructed by using SAS/STAT 9.1.3 (SAS Institute Inc., Cary, NC) to evaluate the ability of CA 19-9 to predict completion of all therapy including PD. The area under the curve (AUC) was calculated to compare the relative value of each test. Optimal cutoff values for each test were established by identifying the cutoff at which the sensitivity and specificity of the test were simultaneously maximized. SPSS 17.0 (SPSS Inc., Chicago, IL) was used for all other statistical analyses. Values of $P \leq 0.05$ were considered to be significant for all comparisons.

\section{RESULTS}

Median survival of the 174 patients was 20 months [95\% confidence interval (CI) 17.0-22.7 months]. Following chemoradiation, $139(80 \%)$ of the 174 patients remained 
candidates for PD based on the clinical restaging evaluation. Of these, $119(86 \%)$ underwent resection and had a median survival of 32 months (95\% CI 25.4-37.6 months). Median survival of all patients $(P=0.08)$ and resected patients $(P=0.21)$ did not differ between treatment protocols. Median follow-up of surviving patients was 78 months.

Pretreatment CA 19-9 was assayed in 166 (95\%) of 174 patients and was evaluable in 99 (median $145 \mathrm{U} / \mathrm{ml}$, mean $595 \pm 1,233 \mathrm{U} / \mathrm{ml}$, range $2-8,614 \mathrm{U} / \mathrm{ml}$ ); the 67 remaining patients had hyperbilirubinemia which precluded accurate evaluation of CA 19-9 levels. Restaging CA 19-9 was assayed in $133(76 \%)$ of 174 patients and was evaluable in 129 (median $44 \mathrm{U} / \mathrm{ml}$, mean $279 \pm 912 \mathrm{U} / \mathrm{ml}$, range 1$6,926 \mathrm{U} / \mathrm{ml}$ ); the 4 remaining patients had a total bilirubin $>1.5 \mathrm{mg} / \mathrm{dl}$ and were excluded from analysis. Of the 99 patients with an evaluable pretreatment CA 19-9 level, 82 (83\%) had an evaluable restaging CA 19-9 (median $42 \mathrm{U} /$ $\mathrm{ml}$, mean $316 \pm 1,078 \mathrm{U} / \mathrm{ml}$, range $1-6,926 \mathrm{U} / \mathrm{ml})$. The demographics, clinical factors, and outcomes of patients with and without evaluable CA 19-9 levels at each time point were similar (Table 1).

\section{Association of Pretreatment CA 19-9 with PD, Postoperative Recurrence, and Survival}

Of 99 patients with an evaluable pretreatment serum CA 19-9 level, 70 (71\%) completed all therapy including PD (median $129 \mathrm{U} / \mathrm{ml}$, mean $581 \pm 1,364 \mathrm{U} / \mathrm{ml}$, range 2$8,614 \mathrm{U} / \mathrm{ml}$ ) and 29 patients did not (median $173 \mathrm{U} / \mathrm{ml}$, mean $629 \pm 856 \mathrm{U} / \mathrm{ml}$, range $12-3,365 \mathrm{U} / \mathrm{ml}, P=0.9)$. The area under the ROC curve for pretreatment CA 19-9 as a marker of completing all therapy including surgical resection was 0.59 (95\% CI 0.47-0.71); the optimal cutoff which simultaneously maximized both the sensitivity (54\%) and specificity (55\%) of the test was $149 \mathrm{U} / \mathrm{ml}$ (Fig. 1).

Pretreatment CA 19-9 was associated with a low negative predictive value (NPV) for completing all therapy including PD at all cutoff values (Table 2). Among 15 patients without documented recurrence following PD, the highest pretreatment CA 19-9 level was $1,125 \mathrm{U} / \mathrm{ml}$ (Fig. 2). In contrast, the positive predictive value (PPV) of pretreatment CA 19-9 for undergoing PD was considerably higher. Patients with a pretreatment CA 19-9 level within the normal range had more favorable survival than those with an elevated pretreatment CA 19-9 $(P=0.02)$, although significance was not maintained when evaluating only those patients who underwent PD $(P=0.08)$.

Association of Restaging CA 19-9 with PD,

Postoperative Recurrence, and Survival

Of the 129 patients in whom restaging levels were evaluable, 108 (84\%) had no evidence of disease progression and performance status sufficient for surgery following induction therapy (median restaging CA $19-940 \mathrm{U} / \mathrm{ml}$, mean $109 \pm 290 \mathrm{U} / \mathrm{ml}$, range 1-2,699 U/ml) and $21 \mathrm{did}$ not (median restaging CA $19-9372 \mathrm{U} / \mathrm{ml}$, mean $1,152 \pm$ $1,981 \mathrm{U} / \mathrm{ml}$, range $13-6,927 \mathrm{U} / \mathrm{ml}, P<0.001)$. In all, 93 (72\%) of 129 patients completed all therapy including PD (median restaging CA 19-9 $34 \mathrm{U} / \mathrm{ml}$, mean $83 \pm 150 \mathrm{U} / \mathrm{ml}$, range $1-934 \mathrm{U} / \mathrm{ml}$ ) and 36 patients did not (median $106 \mathrm{U} / \mathrm{ml}$, mean $785 \pm 1,619 \mathrm{U} / \mathrm{ml}$, range 7-6,927 U/ml, $P<0.001)$.

The AUC for restaging CA 19-9 as a marker of completing all therapy including PD was 0.74 (95\% CI 0.64 $0.84)$; the cutoff that maximized both sensitivity $(72 \%)$ and specificity (69\%) of this test was $61 \mathrm{U} / \mathrm{ml}$ (Table 3, Fig. 1). Independently, the optimal cutoff of $61 \mathrm{U} / \mathrm{ml}$ was associated with an NPV of $49 \%$. The NPV of this cutoff was even lower $(28 \%)$ when the test was applied only to patients who were considered resectable upon restaging; the test therefore had little power to identify patients with radiographically occult disease progression. The highest restaging CA 19-9 level in patients who underwent potentially curative PD was $934 \mathrm{U} / \mathrm{ml}$ (Fig. 3). In contrast, the PPV of the test for completing all therapy including PD was $86 \%$ at a cutoff of $61 \mathrm{U} / \mathrm{ml}$; when evaluated only in the 108 patients with evaluable restaging levels and a performance status suitable for surgery and no evidence of disease progression, the PPV was $93 \%$.

Although restaging CA 19-9 at all cutoff levels was a useful prognostic indicator with regard to overall survival, significance was not maintained when only patients who underwent PD were considered.

\section{Change in CA 19-9 and Correlation with PD, Survival, and Treatment Effect}

Of 82 patients in whom both pretreatment and restaging CA 19-9 levels were evaluable, pretreatment CA 19-9 was $<37 \mathrm{U} / \mathrm{ml}$ in $18(22 \%)$ patients. CA 19-9 remained within the normal range upon restaging in $16(89 \%)$ of these 18 patients; in the remaining 2 patients, CA 19-9 increased only marginally (to 44 and $74 \mathrm{U} / \mathrm{ml}$ ). Therefore, we analyzed the significance of change in serum CA 19-9 between pretreatment and restaging by examining only the 64 patients with pretreatment CA 19-9 above the upper limit of normal. Overall, the 52 patients in whom CA 19-9 levels decreased had more favorable survival than the 12 patients in whom levels remained stable or increased [25.7 months (95\% CI 18.5-32.9 months) versus 10.4 months (95\% CI 0-21.4 months), $P=0.01]$, and were more likely to undergo PD (77\% versus $42 \%, P=0.02)$. However, the median survival of the five patients in whom CA 19-9 did not change or increased over the course of treatment but who underwent PD was similar to that of the 40 patients 
TABLE 1 Demographic profile, clinical factors, and outcomes of 174 patients with resectable PC treated with neoadjuvant chemoradiation

\begin{tabular}{|c|c|c|c|c|c|c|c|c|c|c|}
\hline Clinical factor & $\begin{array}{l}\text { Total } \\
(\%)\end{array}$ & $\begin{array}{l}\text { Pretreatment } \\
\text { CA 19-9 } \\
\text { evaluable }\end{array}$ & $\begin{array}{l}\text { Pretreatment } \\
\text { CA 19-9 not } \\
\text { evaluable }\end{array}$ & $P$ & $\begin{array}{l}\text { Restaging } \\
\text { CA 19-9 } \\
\text { evaluable }\end{array}$ & $\begin{array}{l}\text { Restaging } \\
\text { CA 19-9 not } \\
\text { evaluable }\end{array}$ & $P$ & $\begin{array}{l}\text { Pretreatment } \\
\text { and restaging } \\
\text { CA 19-9 both } \\
\text { evaluable }\end{array}$ & $\begin{array}{l}\text { Pretreatment } \\
\text { and restaging } \\
\text { CA 19-9 both } \\
\text { not evaluable }\end{array}$ & $P$ \\
\hline No. of Patients & 174 & 99 & 75 & & 129 & 45 & & 82 & 92 & \\
\hline \multicolumn{11}{|l|}{ Demographics } \\
\hline Gender, no. (\%) & & & & 0.19 & & & 0.27 & & & 0.12 \\
\hline Male & $104(60)$ & $55(56)$ & $49(65)$ & & $74(57)$ & $30(67)$ & & $44(54)$ & $60(65)$ & \\
\hline Female & $70(40)$ & $44(44)$ & $26(35)$ & & $55(43)$ & $15(33)$ & & $38(46)$ & $32(35)$ & \\
\hline Age, years. & & & & 0.04 & & & 0.78 & & & 0.02 \\
\hline Median (mean) & $64(63)$ & $62(61)$ & $66(64)$ & & $64(63)$ & $64(62)$ & & $62(61)$ & $66(64)$ & \\
\hline Range & $38-80$ & $38-80$ & $43-79$ & & $38-80$ & $43-77$ & & $38-80$ & $43-79$ & \\
\hline \multicolumn{11}{|l|}{ Treatment factors } \\
\hline Treatment protocol, no. (\%) & & & & 0.23 & & & 0.001 & & & 0.05 \\
\hline Gem-XRT & $86(49)$ & $45(46)$ & $41(55)$ & & $54(42)$ & $32(71)$ & & $34(42)$ & $52(57)$ & \\
\hline Gem-Cis-XRT & $88(51)$ & $54(54)$ & $34(45)$ & & $75(58)$ & $13(29)$ & & $48(58)$ & $40(43)$ & \\
\hline Resected, no. (\%) & & & & 0.45 & & & 0.08 & & & 0.20 \\
\hline Yes & $119(68)$ & $70(71)$ & $49(65)$ & & $93(72)$ & $26(58)$ & & $60(73)$ & $59(64)$ & \\
\hline No & $55(32)$ & $29(29)$ & $26(35)$ & & $36(28)$ & $19(42)$ & & $22(27)$ & $33(36)$ & \\
\hline Recurred, no. $(\%)^{\mathrm{a}}$ & & & & 0.51 & & & 0.59 & & & 0.65 \\
\hline Yes & $77(65)$ & $47(67)$ & $30(61)$ & & $59(63)$ & $18(69)$ & & $40(67)$ & $37(63)$ & \\
\hline No & $42(35)$ & $23(33)$ & $19(39)$ & & $34(37)$ & $8(31)$ & & $20(33)$ & $22(37)$ & \\
\hline \multicolumn{11}{|l|}{ Time to recurrence, months } \\
\hline Resected patients & 21.0 & 24.3 & 17.2 & 0.93 & 24.3 & 15.8 & 0.40 & 24.3 & 17.2 & 0.96 \\
\hline $95 \% \mathrm{CI}$ & $12.9-29.0$ & $14.5-34.1$ & $4.4-30.0$ & & $14.5-34.0$ & $8.2-23.4$ & & $15.2-33.3$ & $3.0-31.4$ & \\
\hline \multicolumn{11}{|l|}{ Median OS, months } \\
\hline All patients & 19.8 & 22.9 & 16.9 & 0.30 & 21.7 & 15.3 & 0.03 & 23.9 & 17.4 & 0.20 \\
\hline $95 \% \mathrm{CI}$ & $17.0-22.7$ & $17.2-28.6$ & $12.6-21.2$ & & $16.5-26.9$ & $12.1-18.6$ & & $17.7-30.0$ & $13.3-21.5$ & \\
\hline Resected patients & 31.5 & 33.6 & 31.5 & 0.65 & 34.0 & 22.7 & 0.22 & 33.6 & 31.5 & 0.69 \\
\hline $95 \% \mathrm{CI}$ & $25.4-37.6$ & $26.8-40.4$ & $13.7-49.2$ & & $26.9-41.0$ & $17.1-28.3$ & & $26.6-40.7$ & $17.6-45.4$ & \\
\hline Unresected patients & 10.3 & 10.3 & 10.2 & 0.23 & 10.2 & 10.3 & 0.76 & 9.6 & 10.3 & 0.27 \\
\hline $95 \% \mathrm{CI}$ & $8.8-11.9$ & $6.8-13.9$ & $8.3-12.0$ & & $8.4-12.0$ & $5.9-14.8$ & & $6.8-12.4$ & $8.6-12.0$ & \\
\hline
\end{tabular}

CI confidence interval, Gem-XRT gemcitabine-based chemoradiation, Gem-Cis-XRT systemic gemcitabine/cisplatin followed by gemcitabinebased chemoradiation

${ }^{a}$ One patient had a new primary which was counted as recurrence

who underwent PD after a decline in CA 19-9 [20.9 months (95\% CI 10.7-31.1 months) versus 28.3 months (95\% CI 23.8-32.9 months), $P=0.41]$. The PPV and NPV of a drop in CA 19-9 to predict PD was $77 \%$ and $58 \%$, respectively; when evaluated at restaging only in 54 patients taken to surgery, the PPV and NPV were $89 \%$ and $44 \%$, respectively.

In the 59 patients with both evaluable pretreatment and restaging CA 19-9 levels and a treatment effect score from the PD specimen, no association was observed between the change in serum CA 19-9 over the course of induction therapy and the grade of treatment effect observed in the surgical specimen $(P=0.74)$. Similarly, no association was observed when we analyzed only the 44 patients who underwent $\mathrm{PD}$ and in whom pretreatment CA 19-9 was above the upper limit of normal $(P=0.43)$.

\section{DISCUSSION}

Patients with resectable PC who undergo PD benefit from adjuvant therapy; current trials for resectable disease no longer have a control arm which receives surgery alone. ${ }^{12,23,24}$ Unfortunately, up to $56 \%$ of patients do not receive postoperative therapy when planned, due largely to delayed surgical recovery or early tumor recurrence. ${ }^{25-27}$ Neoadjuvant treatment sequencing ensures that all patients with resectable $\mathrm{PC}$ who undergo PD receive multimodality treatment. Neoadjuvant strategies also lead to lower than 


\section{Sensitivity}

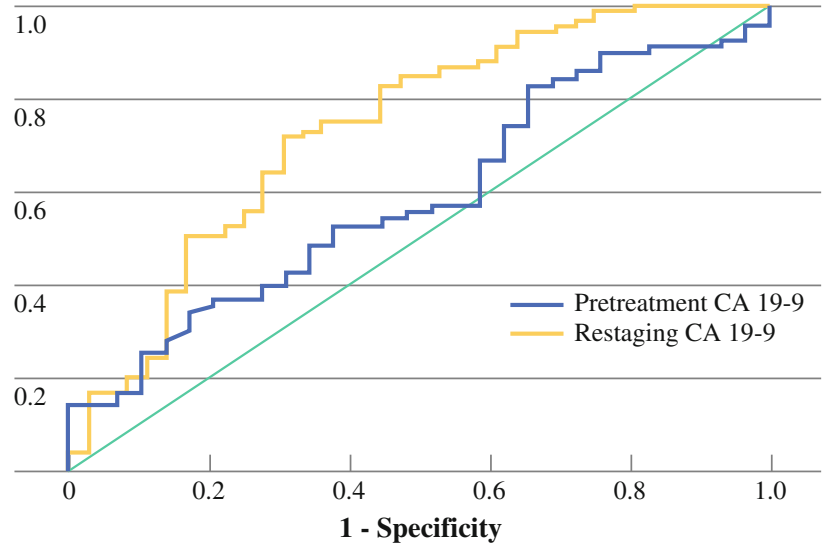

FIG. 1 Receiver-operating characteristics (ROC) curves for pretreatment and restaging serum CA 19-9 levels as predictors of completing all therapy including pancreaticoduodenectomy. The area under the curve (AUC) and optimal cutoff values for pretreatment and restaging CA 19-9 were 0.59 (95\% CI 0.47-0.71), $149 \mathrm{U} / \mathrm{ml}$ and 0.74 (95\% CI $0.64-0.84), 61 \mathrm{U} / \mathrm{ml}$, respectively

expected rates of lymphatic metastasis and positive surgical margins, enrich the population of patients who undergo PD with those most likely to benefit from surgery, and contribute to actual 5-year survival rates as high as $27 \% .^{28-30}$ Successful neoadjuvant treatment approaches require sequential staging evaluations to select those patients who will benefit from surgery-perhaps best considered as one of the earliest forms of personalized cancer care. We performed this analysis to determine whether CA 19-9 could prospectively identify those patients in whom radiographically occult advanced disease will preclude completion of a multidisciplinary strategy employing neoadjuvant therapy and PD.

An elevated CA 19-9 level at diagnosis in patients with radiographically resectable PC has been reported to signify occult disease that will prohibit primary resection. ${ }^{8,10}$ Our results suggest that this is not necessarily the case when surgery is preceded by induction therapy. Indeed, of 78 patients with an evaluable pretreatment CA 19-9 level above the normal range, 52 (67\%) underwent PD, of whom $15(22 \%)$ died of another cause or had not recurred at last follow-up. All patients in our study with an evaluable pretreatment CA 19-9 level greater than 1,125 U/ml either did not undergo PD or ultimately recurred after PD. However, although small patient numbers preclude rigorous statistical analysis, it is interesting that 9 of $16(56 \%)$ patients with radiographically resectable disease and a pretreatment CA 19-9 level $\geq 1,000 \mathrm{U} / \mathrm{ml}$ underwent PD following neoadjuvant therapy, only 4 of these 9 patients recurred within 2 years, and the median overall survival of these resected patients approached 3 years. It may be that the antitumor effects of induction therapy alter the expected relationship between CA 19-9 and tumor burden over time. Our study assessed CA 19-9 only in the setting of normal bilirubin and included a more homogenous population of patients than prior studies, which also may have made differences between patient subgroups more subtle. Either way, these data support caution in the use of pretreatment CA 19-9 as an eligibility criterion for enrollment into clinical trials of neoadjuvant therapies for patients with resectable PC, as has been employed in trials of postoperative therapy (i.e., CONKO-001). ${ }^{12}$

Pretreatment CA 19-9 has also been reported to be a marker of overall prognosis for patients treated with initial surgery. ${ }^{8,31}$ In this analysis, pretreatment CA 19-9 within the normal range was associated with favorable overall survival. Our inability to demonstrate similar prognostic power when a cutoff of $37 \mathrm{U} / \mathrm{ml}$ was applied to the subgroup of patients who underwent PD may be due to the relatively small number of patients analyzed. Nonetheless,

TABLE 2 Resection rate and overall survival of 99 patients with evaluable pretreatment CA 19-9 levels stratified by cutoff

\begin{tabular}{|c|c|c|c|c|c|c|c|c|}
\hline \multirow{2}{*}{$\begin{array}{l}\text { Pretreatment CA } \\
19-9(\mathrm{U} / \mathrm{ml})\end{array}$} & \multicolumn{3}{|c|}{ Total patients } & \multicolumn{5}{|l|}{ Resected patients } \\
\hline & $N(\%)$ & $\begin{array}{l}\text { Overall survival, } \\
\text { months }(95 \% \mathrm{CI})\end{array}$ & $P$ & Resected $n(\%)$ & $P$ & $\begin{array}{l}\text { Test characteristics for } \\
\text { undergoing resection }\end{array}$ & $\begin{array}{l}\text { Overall survival, } \\
\text { months }(95 \% \mathrm{CI})\end{array}$ & $P$ \\
\hline Evaluable & 99 & $22.9(17.2-28.6)$ & & $70(71)$ & & & $33.6(26.8-40.4)$ & \\
\hline$<37$ & $21(21)$ & $52.8(5.4-100.1)$ & 0.02 & $18(86)$ & 0.09 & Sens $26 \%$ Spec $90 \%$ & $83.4(21.9-145.0)$ & 0.08 \\
\hline$\geq 37$ & $78(79)$ & $21.2(16.7-25.7)$ & & $52(67)$ & & PPV $86 \%$ NPV $33 \%$ & $28.1(22.8-33.4)$ & \\
\hline$<149^{\mathrm{a}}$ & $51(52)$ & $25.7(18.0-33.4)$ & 0.08 & $38(75)$ & 0.39 & Sens $54 \%$ Spec $55 \%$ & $12.8(13.4-63.7)$ & 0.20 \\
\hline$\geq 149^{\mathrm{a}}$ & $48(48)$ & 20.9 (12.3-29.5) & & $32(67)$ & & PPV $75 \%$ NPV $33 \%$ & $28.3(18.3-38.4)$ & \\
\hline$<200$ & $58(59)$ & $22.9(16.0-29.7)$ & 0.37 & $41(71)$ & 0.99 & Sens $59 \%$ Spec $41 \%$ & $35.2(20.5-50.0)$ & 0.40 \\
\hline$\geq 200$ & $41(41)$ & $21.4(14.6-28.2)$ & & $29(71)$ & & PPV $71 \%$ NPV $29 \%$ & $31.0(20.2-41.8)$ & \\
\hline$<1,000$ & $83(84)$ & $22.9(17.4-28.3)$ & 0.34 & $61(73)$ & 0.17 & Sens $87 \%$ Spec $24 \%$ & $33.6(26.5-40.7)$ & 0.98 \\
\hline$\geq 1,000$ & $16(16)$ & $19.7(0-41.7)$ & & $9(56)$ & & PPV $73 \%$ NPV $44 \%$ & $35.9(12.2-59.6)$ & \\
\hline
\end{tabular}

Sens sensitivity, Spec specificity, $P P V$ positive predictive value, $N P V$ negative predictive value

${ }^{a}$ Optimal pretreatment CA 19-9 cutoff determined by receiver-operating characteristics (ROC) analysis 


\section{Pretreatment}

CA 19-9 (U/ml)

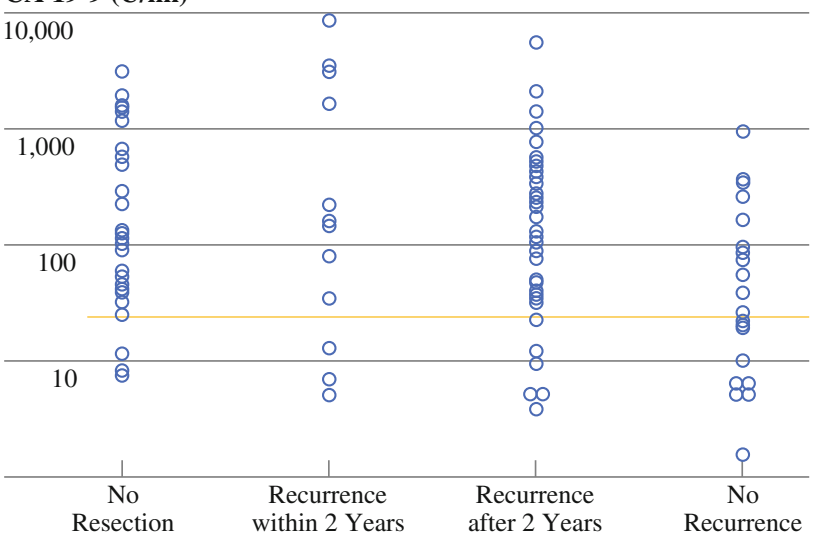

Clinical Group

FIG. 2 Pretreatment serum CA 19-9 levels of patients stratified by resection and recurrence status at last follow-up. Of 78 patients with pretreatment CA 19-9 above normal, 52 (67\%) underwent resection, of whom $15(22 \%)$ died of another cause or had not recurred at last follow-up. Y-axis scale is $\log _{10}$. Horizontal line represents $37 \mathrm{U} / \mathrm{ml}$

our data, combined with those of Berger et al., suggest that a normal CA 19-9 level upon diagnosis may indicate slightly more favorable tumor biology independent of the initial therapeutic approach. ${ }^{31}$

Response of CA 19-9 to surgical and adjuvant therapy has been reported to be a measure of therapeutic efficacy. ${ }^{8,11}$ Four analyses have examined the change in CA 19-9 over the course of nonoperative therapies prior to surgery. Three of these were small studies analyzing primarily patients with advanced, nonsurgical disease, who were treated in the absence of a defined plan for resection. ${ }^{16-18}$ The results of these studies suggested the possibility that CA 19-9 might be used as a crude measure of response to preoperative therapy. However, the

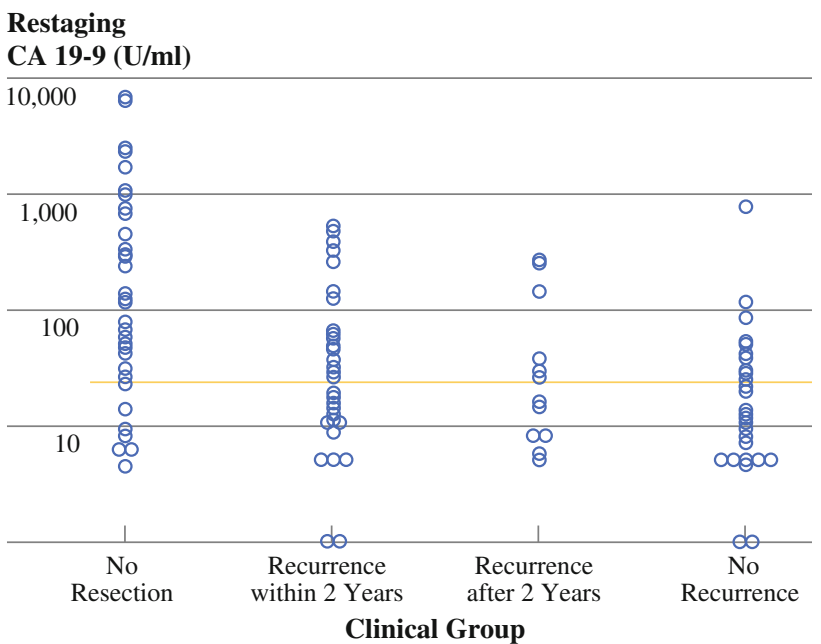

FIG. 3 Restaging serum CA 19-9 levels of patients stratified by resection and recurrence status at last follow-up. No patient with a restaging CA $19-9 \geq 1,000 \mathrm{U} / \mathrm{ml}$ underwent resection. $Y$-axis scale is $\log _{10}$. Horizontal line represents $37 \mathrm{U} / \mathrm{ml}$

heterogeneity of the patient populations studied makes this conclusion difficult to apply to individual patients with resectable disease who are being considered for neoadjuvant treatment prior to planned PD. Indeed, a recent prospective study of neoadjuvant chemoradiation prior to planned resection in 28 patients with resectable PC was unable to demonstrate any correlation between change in CA 19-9 and therapeutic response or ultimate resectability. ${ }^{15}$ Importantly, this study was small and did not take into account the effects of hyperbilirubinemia; the changes observed in CA 19-9 over the course of induction therapy may have been influenced by biliary decompression and not the anticancer therapy alone.

Data from the 82 patients in our study in whom both pretreatment and restaging CA 19-9 levels were evaluable

TABLE 3 Resection rate and overall survival of 129 patients with evaluable restaging CA 19-9 levels stratified by cutoff

\begin{tabular}{|c|c|c|c|c|c|c|c|c|}
\hline \multirow{2}{*}{$\begin{array}{l}\text { Restaging CA } \\
19-9(\mathrm{U} / \mathrm{ml})\end{array}$} & \multicolumn{3}{|c|}{ Total patients } & \multicolumn{5}{|c|}{ Resected patients } \\
\hline & $N(\%)$ & $\begin{array}{l}\text { Overall survival, } \\
\text { months }(95 \% \mathrm{CI})\end{array}$ & $P$ & $\begin{array}{l}\text { Resected } \\
n(\%)\end{array}$ & $P$ & $\begin{array}{l}\text { Test characteristics for } \\
\text { undergoing resection }\end{array}$ & $\begin{array}{l}\text { Overall survival, } \\
\text { months }(95 \% \mathrm{CI})\end{array}$ & $P$ \\
\hline Evaluable & 129 & 21.7 (16.5-26.9) & & $93(72)$ & & & $24.3(16.2-32.3)$ & \\
\hline$<37$ & $55(43)$ & $24.3(12.2-36.4)$ & 0.01 & $47(85)$ & 0.004 & Sens $50 \%$ Spec $78 \%$ & $37.1(10.6-63.6)$ & 0.30 \\
\hline$\geq 37$ & $74(57)$ & $13.1(11.9-14.4)$ & & $46(62)$ & & PPV $85 \%$ NPV $38 \%$ & $31.0(24.4-37.6)$ & \\
\hline$<61^{\mathrm{a}}$ & $78(60)$ & $21.2(11.9-30.6)$ & 0.001 & $67(86)$ & $<0.001$ & Sens $72 \%$ Spec $69 \%$ & $36(20.2-51.8)$ & 0.38 \\
\hline$\geq 61^{\mathrm{a}}$ & $51(40)$ & $12.7(10.8-14.6)$ & & $26(51)$ & & PPV $86 \%$ NPV $49 \%$ & $28.3(13.1-43.5)$ & \\
\hline$<200$ & $106(82)$ & $26.4(20.2-32.6)$ & $<0.001$ & $84(79)$ & $<0.001$ & Sens $90 \%$ Spec $39 \%$ & $36.0(24.0-48.0)$ & 0.21 \\
\hline$\geq 200$ & $23(18)$ & $10.4(8.5-12.3)$ & & $9(39)$ & & PPV $79 \%$ NPV $61 \%$ & $28.3(8.1-48.6)$ & \\
\hline$<1,000$ & $122(95)$ & $15.2(12.3-18.2)$ & $<0.001$ & $93(76)$ & $<0.001$ & Sens $100 \%$ Spec $19 \%$ & $34.0(26.9-41.0)$ & NA \\
\hline$\geq 1,000$ & $7(5)$ & $9.1(0.8-17.4)$ & & $0(0)$ & & PPV $76 \%$ NPV $100 \%$ & NA & \\
\hline
\end{tabular}

Sens sensitivity, Spec specificity, $P P V$ positive predictive value, $N P V$ negative predictive value, $N A$ not applicable

${ }^{a}$ Optimal pretreatment CA 19-9 cutoff determined by receiver-operating characteristics (ROC) analysis 
affirm that both the restaging CA 19-9 level and the change in CA 19-9 over the course of neoadjuvant therapy are clinically relevant prognostic markers; in general, low restaging values are better than high values, and a decline in CA 19-9 following induction therapy is more favorable than a rise. However, four important caveats must be noted with regard to these observations. First, the PPV of the restaging CA 19-9 (86\%) and the change in CA 19-9 (77\%) for completing all therapy including PD were similar to that of the standard restaging evaluation (radiography and physical examination) alone (86\%). Second, restaging CA 19-9 and its change from the pretreatment level were both associated with low NPV for competing PD; therefore, neither test effectively excluded radiographically occult metastatic disease at time of restaging. Third, although the number of patients analyzed was relatively small, the median survival of patients who underwent PD in the setting of restaging CA 19-9 higher than all cutoff values, or with stable or increased restaging CA 19-9, was similar to the median survival of patients who underwent $\mathrm{PD}$ in whom CA 19-9 levels were below each cutoff value or fell. Finally, we were unable to demonstrate any correlation between change in CA 19-9 level and response to treatment as assessed histopathologically.

This study has two potential limitations. The first is our inability to differentiate between patients with low but detectable level of CA 19-9 and patients with Lewis ${ }^{\text {a-b- }}$ blood type who do not secrete CA $19-9 .{ }^{22}$ The extent to which our results have been influenced by this is difficult to determine as few studies have examined the prognosis of Lewis antigen-negative patients. Available data suggest that Lewis $^{\mathrm{a}-\mathrm{b}-}$ patients have a prognosis similar to, but perhaps even more favorable than, patients with CA 19-9 levels that are detectable but within the normal range or slightly elevated. ${ }^{11,31}$ Future trials are necessary to clearly define the cancer biology of this group of patients.

A second potential limitation of this study is the exclusion of significant numbers of patients from analysis due to elevation in serum bilirubin. This is particularly true in the pretreatment setting: 67 of 174 patients with an available pretreatment CA 19-9 level were excluded from analysis due to concomitant obstructive jaundice. Hyperbilirubinemia, however, can confound measurements of CA 19-9 levels and can introduce significant error into analyses in which CA 19-9 levels associated with both normal and elevated bilirubin levels are considered. ${ }^{7,21}$ Indeed, as we have argued, this represents a major limitation of other studies. ${ }^{10,15}$ Importantly, we found that the demographics, clinical factors, and outcomes of patients with and without an evaluable CA 19-9 at each time point were comparable, suggesting that the exclusion criteria used in this study actually strengthen our conclusions (as opposed to weaken them).
In summary, based upon these data, we offer the following conclusions with regard to use of CA 19-9 in the evaluation of patients with resectable PC treated with neoadjuvant therapy. Serum CA 19-9 levels within the normal range at diagnosis will most often remain normal after induction therapy, and patients with a normal pretreatment CA 19-9 level can be expected to have favorable prognosis compared with those with an elevated level. Nonetheless, the presence of an elevated pretreatment serum CA 19-9 level may not preclude completion of all therapy to include PD. Similarly, both a low restaging CA 19-9 level and a decline over the course of induction therapy are associated with undergoing successful PD; however, a persistently elevated CA 19-9 level at restaging does not reliably signify disease progression and may not preclude successful PD. Based upon these findings, we recommend that therapeutic decision-making with regard to use of neoadjuvant therapy and PD for patients with potentially resectable PC remain largely based on expert clinical assessment and high-quality radiographic staging.

ACKNOWLEDGMENT Supported by the Hamill Foundation, the Various Donor Fund for Pancreatic Cancer Research, and National Institutes of Health grant CA101936-01 (SPORE in Pancreatic Cancer) at The University of Texas M. D. Anderson Cancer Center.

OPEN ACCESS This article is distributed under the terms of the Creative Commons Attribution Noncommercial License which permits any noncommercial use, distribution, and reproduction in any medium, provided the original author(s) and source are credited.

\section{REFERENCES}

1. Raut CP, Evans DB, Crane CH, Pisters PW, Wolff RA. Neoadjuvant therapy for resectable pancreatic cancer. Surg Oncol Clin North Am. 2004;13:639-61.

2. Evans DB, Varadhachary GR, Crane $\mathrm{CH}$, et al. Preoperative gemcitabine-based chemoradiation for patients with resectable adenocarcinoma of the pancreatic head. $J$ Clin Oncol. 2008;26:3496-502.

3. Varadhachary GR, Wolff RA, Crane $\mathrm{CH}$, et al. Preoperative gemcitabine and cisplatin followed by gemcitabine-based chemoradiation for resectable adenocarcinoma of the pancreatic head. J Clin Oncol. 2008;26:3487-95.

4. Talamonti MS, Small W Jr, Mulcahy MF, et al. A multi-institutional phase II trial of preoperative full-dose gemcitabine and concurrent radiation for patients with potentially resectable pancreatic carcinoma. Ann Surg Oncol. 2006;13:150-8.

5. Stessin AM, Meyer JE, Sherr DL. Neoadjuvant radiation is associated with improved survival in patients with resectable pancreatic cancer: an analysis of data from the surveillance, epidemiology, and end results (SEER) registry. Int $J$ Radiat Oncol Biol Phys. 2008;72:1128-33.

6. Pisters PW. ACOSOG Z5041: A phase II study of preoperative gemcitabine and erlotinib plus pancreatectomy and postoperative gemcitabine and erlotinib for patients with operable pancreatic adenocarcinoma, 2009.

7. Katz MH, Moossa AR, Bouvet M. Serologic diagnosis of pancreatic cancer. In: Von Hoff D, Evans DB, Hruban R, editors. 
Pancreatic cancer. Sudbury, MA: Jones and Bartlett; 2005. p. 235-250.

8. Ferrone CR, Finkelstein DM, Thayer SP, Muzikansky A, Fernandez-del Castillo C, Warshaw AL. Perioperative CA19-9 levels can predict stage and survival in patients with resectable pancreatic adenocarcinoma. J Clin Oncol. 2006;24:2897-902.

9. Schlieman MG, Ho HS, Bold RJ. Utility of tumor markers in determining resectability of pancreatic cancer. Arch Surg. 2003;138:951-5; discussion 955-956.

10. Maithel SK, Maloney S, Winston C, et al. Preoperative CA 19-9 and the yield of staging laparoscopy in patients with radiographically resectable pancreatic adenocarcinoma. Ann Surg Oncol. 2008:15:3512-20.

11. Berger AC, Garcia M Jr, Hoffman JP, et al. Postresection CA 199 predicts overall survival in patients with pancreatic cancer treated with adjuvant chemoradiation: a prospective validation by RTOG 9704. J Clin Oncol. 2008;26:5918-22.

12. Oettle H, Post $S$, Neuhaus $P$, et al. Adjuvant chemotherapy with gemcitabine vs observation in patients undergoing curative-intent resection of pancreatic cancer: a randomized controlled trial. JAMA. 2007;297:267-77.

13. Hess V, Glimelius B, Grawe P, et al. CA 19-9 tumour-marker response to chemotherapy in patients with advanced pancreatic cancer enrolled in a randomised controlled trial. Lancet Oncol. 2008;9:132-8.

14. Maisey NR, Norman AR, Hill A, Massey A, Oates J, Cunningham D. CA19-9 as a prognostic factor in inoperable pancreatic cancer: the implication for clinical trials. $\mathrm{Br} J$ Cancer. 2005;93:740-3.

15. Heinrich S, Schafer M, Weber A, Hany TF, Bhure U, Pestalozzi $\mathrm{BC}$, et al. Neoadjuvant chemotherapy generates a significant tumor response in resectable pancreatic cancer without increasing morbidity: results of a prospective phase II trial. Ann Surg. 2008;248:1014-22.

16. Ohara K, Tatsuzaki H, Molotkova NG, et al. Utility of serum CA 19-9 monitoring in preoperative radiotherapy for pancreatic cancer. Hepatogastroenterology. 2001;48:859-63.

17. Willett CG, Daly WJ, Warshaw AL. CA 19-9 is an index of response to neoadjunctive chemoradiation therapy in pancreatic cancer. Am J Surg. 1996;172:350-2.

18. Small W Jr, Berlin J, Freedman GM, et al. Full-dose gemcitabine with concurrent radiation therapy in patients with nonmetastatic pancreatic cancer: a multicenter phase II trial. J Clin Oncol. 2008;26:942-7.
19. Yen T, Abdalla E, Pisters PW, Evans DB. Pancreaticoduodenectomy. In: Von Hoff D, Evans DB, Hruban R, editors. Pancreatic cancer. Sudbury, MA: Jones and Bartlett; 2005. p. 265-286.

20. Evans DB, Rich TA, Byrd DR, et al. Preoperative chemoradiation and pancreaticoduodenectomy for adenocarcinoma of the pancreas. Arch Surg. 1992;127:1335-9.

21. Kang CM, Kim JY, Choi GH, Kim KS, Choi JS, Lee WJ, et al. The use of adjusted preoperative CA 19-9 to predict the recurrence of resectable pancreatic cancer. J Surg Res. 2007;140:31-5.

22. Tempero MA, Uchida E, Takasaki H, Burnett DA, Steplewski Z, Pour PM. Relationship of carbohydrate antigen 19-9 and Lewis antigens in pancreatic cancer. Cancer Res. 1987;47:5501-3.

23. Kalser MH, Ellenberg SS. Pancreatic cancer. Adjuvant combined radiation and chemotherapy following curative resection. Arch Surg. 1985;120:899-903.

24. Neoptolemos JP, Stocken DD, Friess H, et al. A randomized trial of chemoradiotherapy and chemotherapy after resection of pancreatic cancer. $N$ Engl J Med. 2004;350:1200-10.

25. Corsini MM, Miller RC, Haddock MG, et al. Adjuvant radiotherapy and chemotherapy for pancreatic carcinoma: the Mayo Clinic experience (1975-2005). J Clin Oncol. 2008;26:3511-16.

26. Herman JM, Swartz MJ, Hsu CC, et al. Analysis of fluorouracilbased adjuvant chemotherapy and radiation after pancreaticoduodenectomy for ductal adenocarcinoma of the pancreas: results of a large, prospectively collected database at the Johns Hopkins Hospital. J Clin Oncol. 2008;26:3503-10.

27. Aloia TA, Lee JE, Vauthey JN, et al. Delayed recovery after pancreaticoduodenectomy: a major factor impairing the delivery of adjuvant therapy? J Am Coll Surg. 2007;204:347-55.

28. Pingpank JF, Hoffman JP, Ross EA, et al. Effect of preoperative chemoradiotherapy on surgical margin status of resected adenocarcinoma of the head of the pancreas. J Gastrointest Surg. 2001;5:121-30.

29. Raut CP, Tseng JF, Sun CC, et al. Impact of resection status on pattern of failure and survival after pancreaticoduodenectomy for pancreatic adenocarcinoma. Ann Surg. 2007;246:52-60.

30. Katz MH, Wang H, Fleming JB, et al. Long-term survival after multidisciplinary management of resected pancreatic adenocarcinoma. Ann Surg Oncol. 2009;16:836-47.

31. Berger AC, Meszoely IM, Ross EA, Watson JC, Hoffman JP. Undetectable preoperative levels of serum CA 19-9 correlate with improved survival for patients with resectable pancreatic adenocarcinoma. Ann Surg Oncol. 2004;11:644-9. 